\title{
Microwell Scaffolds Using Collagen-IV and Laminin- 111 Lead to Improved Insulin Secretion of Human Islets
}

Citation for published version (APA):

Hadavi, E., Leijten, J., Engelse, M., de Koning, E., Jonkheijm, P., Karperien, M., \& van Apeldoorn, A. (2019). Microwell Scaffolds Using Collagen-IV and Laminin-111 Lead to Improved Insulin Secretion of Human Islets. Tissue Engineering. Part C. Methods , 25(2), 71-81.

https://doi.org/10.1089/ten.tec.2018.0336

Document status and date:

Published: 01/02/2019

DOI:

10.1089/ten.tec.2018.0336

Document Version:

Publisher's PDF, also known as Version of record

\section{Document license:}

Taverne

Please check the document version of this publication:

- A submitted manuscript is the version of the article upon submission and before peer-review. There can be important differences between the submitted version and the official published version of record.

People interested in the research are advised to contact the author for the final version of the publication, or visit the DOI to the publisher's website.

- The final author version and the galley proof are versions of the publication after peer review.

- The final published version features the final layout of the paper including the volume, issue and page numbers.

Link to publication

\footnotetext{
General rights rights.

- You may freely distribute the URL identifying the publication in the public portal. please follow below link for the End User Agreement:

www.umlib.nl/taverne-license

Take down policy

If you believe that this document breaches copyright please contact us at:

repository@maastrichtuniversity.nl

providing details and we will investigate your claim.
}

Copyright and moral rights for the publications made accessible in the public portal are retained by the authors and/or other copyright owners and it is a condition of accessing publications that users recognise and abide by the legal requirements associated with these

- Users may download and print one copy of any publication from the public portal for the purpose of private study or research.

- You may not further distribute the material or use it for any profit-making activity or commercial gain

If the publication is distributed under the terms of Article $25 \mathrm{fa}$ of the Dutch Copyright Act, indicated by the "Taverne" license above, 


\title{
Microwell Scaffolds Using Collagen-IV and Laminin-111 Lead to Improved Insulin Secretion of Human Islets
}

\author{
Elahe Hadavi, $\mathrm{PhD}$, Jeroen Leijten, $\mathrm{PhD}$, ${ }^{1}$ Marten Engelse, $\mathrm{PhD}$, ${ }^{2}$ Eelco de Koning, $\mathrm{PhD}$, ,3 \\ Pascal Jonkheijm, PhD, ${ }^{4}$ Marcel Karperien, $\mathrm{PhD},{ }^{1}$ and Aart van Apeldoorn, $\mathrm{PhD}^{1,5}$
}

Intrahepatic islet transplantation is a promising therapy for treatment of type 1 diabetes. During islet isolation, collagenase is used to extract islets from the pancreas, leading to loss of important cell-matrix interactions. Loss of the native pancreatic microenvironment is associated with apoptosis of islet cells, early graft failure, and poor islet function. The islet extracellular matrix (ECM) is composed of a specific combination of collagen (Col), laminin $(\mathrm{LN})$, and fibronectin $(\mathrm{FN})$ molecules. Reintroducing these molecules has been shown to boost the function, viability, morphology, and proliferation of $\beta$-cells. In this research, the effect of combinatorial ECM on islet function and survival was investigated. Specifically, thin-film microwell array scaffolds made from two distinct biomaterials were coated with FN, collagen type IV (Col4), LN111, LN332, or a combination thereof. We found that coatings containing a single type of ECM molecule, for example, FN or Col, can improve short-term islet function. However, these single proteins do not prevent loss of morphology and subsequent loss of islet function afterward. In contrast, combining Col4 with LN111 at a ratio of 8:2 not only improved short-term islet function but also preserved islet structure and islet function on a longer term. This effect was reproducibly shown on poly(esterurethane) and poly(ethylene-glycol-terephthalate-poly(butylene-terephthalate) microwell islet delivery devices as well as tissue culture polystyrene. We concluded that biofunctionalization of inert biomaterials regardless of their molecular composition with a specific combination of islet ECM molecules can support and improve islet function over longer time periods. Our data suggested that creating a biomimetic islet niche by biofunctionalization of biomaterials can significantly improve the endocrine function of $\beta$-cells. The creation of islet mimicking niches in islet delivery devices leads to an improvement of islet function by restoring part of the islet's ECM in these devices.

Keywords: microwell scaffolds, ECM, islet function, insulin secretion, type 1 diabetes

\section{Impact Statement}

This research deals with finding a proper bioengineering strategy to improve the outcome of islets transplantation for treatment of type 1 diabetes. It is focused on the mimicking of islet extracellular matrix niche in microwell islet delivery devices to improve their endocrine function.

\section{Introduction}

NTRAHEPATIC ISLET TRANSPLANTATION is a minimally invasive therapy to treat type 1 diabetes by replacing lost $\beta$-cells. This treatment results in insulin independence in $50 \%$ of the transplanted patients for a period of $3-5$ years. ${ }^{1}$ The success of islet transplantation is significantly influenced by the process of islet isolation from the pancreas. Current islet isolation methods result in separation of islets from their surrounding microenvironment by enzymatic digestion of the

\footnotetext{
${ }^{1}$ Department of Developmental BioEngineering, Faculty of Science and Technology, Technical Medical Centre, University of Twente, Enschede, The Netherlands.

${ }^{2}$ Department of Nephrology, Leiden University Medical Center, Leiden, The Netherlands.

${ }^{3}$ Hubrecht Institute, Utrecht, The Netherlands.

${ }^{4}$ Bioinspired Molecular Engineering Laboratory and Molecular Nanofabrication Group, MESA+ Institute for Nanotechnology, University of Twente, Enschede, The Netherlands.

${ }^{5}$ Department of Complex Tissue Regeneration, MERLN Institute for Technology Inspired Regenerative Medicine, Maastricht University, Maastricht, The Netherlands.
} 
pancreatic extracellular matrix (ECM). Degradation of the ECM not only affects islet physiology but also negatively affects insulin gene expression, ${ }^{2}$ insulin secretion, ${ }^{3}$ proliferation ${ }^{4}$ differentiation, ${ }^{4,5}$ adhesion, and survival of $\beta$-cells. ${ }^{6-8}$ Therefore, degradation or removal of islets ECM molecules such as collagen ( $\mathrm{Col})$, fibronectin (FN), and laminin ( $\mathrm{LN}$ ) during islet isolation can reduce the efficacy of islet transplantation by providing a suboptimal $\beta$-cell microenvironment.

To overcome problems associated with the removal of ECM molecules after islet isolation, several researchers have investigated the addition of a new ECM to isolated islets. Results of these studies revealed the beneficial shortterm effects of a new ECM on islet function. For instance, the mechanical support and topological arrangement of the islet's endocrine cells were improved in the presence of certain ECM molecules. Consequently, insulin secretion and islet survival were enhanced in these studies. ${ }^{9}$ More specifically, it was reported that a combination of collagen type I (Col1) and collagen type IV (Col4) improves the insulin secretion of $\beta$-cell. ${ }^{10}$ In another study, it was shown that culturing islets in Coll hydrogels mixed with $\mathrm{Col3}$, Col4, and LN improves the survival of the islets. ${ }^{11}$ The ECM molecules secreted by $804 \mathrm{G}$ cells increase the insulin release of $\beta$-cells. ${ }^{12}$ The specific sequence of LN511 promotes islet viability as well as insulin release. Moreover, the synergistic beneficial effect of the leu-arg-glu sequence of $\mathrm{LN}$ in combination with Col4 was reported. ${ }^{13}$ In addition, some studies focused on the interaction of ECM molecules with integrin and nonintegrin receptors that are expressed by human islets. Such interactions regulate adhesion, differentiation, insulin secretion, and survival of $\beta$-cells. For instance, human $\beta$-cell adhesion, motility, and insulin secretion were associated with the interaction of Col4 and its specific integrin receptors $\left(\alpha_{1} \beta_{1}\right){ }^{3}$ The $\beta$-cells are also known to bind arginine-glycin-aspartic acid (RGD) sequences present in ECM molecules by expressing integrin $\alpha_{3} \beta_{1}, \alpha_{5} \beta_{1}$, and $\alpha_{\mathrm{v}} \beta_{3}$ and thereby promoting cell survival. ${ }^{7}$ Therefore, it is highly important to increase knowledge about the response of human islet cells upon their interaction with ECM molecules.

Previous research has mainly focused on the effect of specific individual ECM proteins on the function and survival of islet cells. However, studies on the combinatorial effects of different ECM molecules at different ratios on islets are lacking. Considering that the islet microenvironment is a complex system and the success of islet transplantation relies on better simulation of the islet microenvironment, a profound investigation of this complexity is necessary. It is important to discover the most effective combination of ECM molecules in a topologically similar microenvironment.

Here, we report about thin-film microwell array scaffolds using a poly(ethylene-glycol-terephthalate-poly(butyleneterephthalate) (4000PEOT30PBT70) abbreviated as (PEOTPBT) and a poly(ester-urethane) to deliver islets. The poly(ester-urethane) was synthesized by reaction of an $\alpha, \omega$-isocyanate end-functionalized prepolyester and an $\alpha, \omega$-hydroxy biscarbamate. The scaffolds were coated with combinations of $\mathrm{FN}, \mathrm{Col} 4$, as well as various LNs, and afterward, the glucose responsiveness of human islet inside these devices was investigated. We showed that a combination of laminin-111 (LN111) and Col4 has a reproducible synergistic positive effect on the function of the human islets. Furthermore, the shape and dimensions of the microwell scaffolds used offer a potential advantage to support the three-dimensional (3D) structure of islets. Interestingly, the positive effect on endocrine function was independent of the biomaterial used to manufacture the microwell scaffold, and not only the amount of insulin secreted by the islets was significantly increased but also their stimulation index was higher in the presence of Col4 and LN in a ratio of $8: 2$.

\section{Materials and Methods \\ Fabrication of PEOT-PBT and poly(ester-urethane) films}

The PEOT-PBT block copolymer is composed of a soft hydrophilic segment poly(ethylene-glycol-terephthalate) and a hard hydrophobic segment poly(butylene-terephthalate) and was produced by PolyVation BV (Groningen, The Netherlands, under the trade name PolyActive ${ }^{\mathrm{TM}}$ ). PEOT is synthesized using poly(ethylene-glycol) with a molecular weight of 4000, whereas the weight percentage of PEOT and PBT is kept at 30:70 wt \%, respectively. ${ }^{14}$ Films with a thickness of $40 \mu \mathrm{m}$ were created using a solvent casting method. Shortly, PEOT-PBT was dissolved in a $65: 35(\mathrm{w} / \mathrm{w})$ mixture of chloroform (Merck, Darmstadt, Germany) and 1,1,1,3,3,3hexafluoro-2-isopropanol (Biosolve, Valkenswaard, The Netherlands) at a concentration of $15 \mathrm{wt} \%$. After casting the polymer solution on a silicon wafer at room temperature, a nitrogen flow was applied for $4 \mathrm{~h}$ to dry the resulting film. Residual solvent was removed by immersing the polymer film in ethanol. Complete evaporation of residual solvents was achieved by placing the films in a vacuum oven (Heraeus, Hanau, Germany) at $30^{\circ} \mathrm{C}$ for 3 days. The same protocol was applied to fabricate poly(ester-urethane) (Polyganics BV, Groningen, The Netherlands) films with a thickness of $40 \mu \mathrm{m}$ from a $5 \mathrm{wt} \%$ polymer solution in chloroform. The poly(ester-urethane) was synthesized by reaction of an $\alpha, \omega$-isocyanate end-functionalized prepolyester and an $\alpha, \omega$-hydroxy biscarbamate.

\section{Preparation of PEOT-PBT and poly(ester-urethane) microwell scaffolds}

Micro thermoforming was applied to manufacture microwell scaffolds with a 3D microwell structure as was reported before. ${ }^{15}$ The backing film materials used for micro thermoforming of PEOT-PBT and poly(ester-urethane) microwell scaffolds consisted of either polyethylene $(560 \mu \mathrm{m}$ thickness) or paraffin (540 $\mu \mathrm{m}$ thickness) placed on top of a $20-\mu \mathrm{m}$-thick polyethylene film, respectively. The films were placed on stainless steel mold created by laser micromachining (Lightmotif BV, Enschede, The Netherlands). For the poly(ester-urethane) microwell scaffold, the initial mold pressure was set at $30 \mathrm{kN}$ at $25^{\circ} \mathrm{C}$, after which the temperature was gradually increased over time. During this process, the pressure was stepwise increased at $30^{\circ} \mathrm{C}, 33^{\circ} \mathrm{C}$, and $41^{\circ} \mathrm{C}$ to 40,50 , and $60 \mathrm{kN}$, respectively. The pressure was released as soon as the temperature reached $41^{\circ} \mathrm{C}$, followed by immersion in ice-cold ethanol for $15 \mathrm{~min}$. Subsequently, the films were gently peeled off their molds. Any residual traces on the poly(ester-urethane) scaffolds of paraffin were removed by immersing the microwells in 
xylene for 1 min followed by five times rinsing with $70 \%$ ethanol and then water. Fabrication of PEOT-PBT microwell scaffolds was performed in a slightly different way. In short, the mold pressure was set at $40 \mathrm{kN}$ at $30^{\circ} \mathrm{C}$. The pressure was kept constant at $40 \mathrm{kN}$, whereas the temperature was increased to $85^{\circ} \mathrm{C}$. At $85^{\circ} \mathrm{C}$, the pressure was increased to $65 \mathrm{kN}$, and directly thereafter, the temperature was set to $20^{\circ} \mathrm{C}$. As soon as the press device was cooled to $20^{\circ} \mathrm{C}$, the pressure was released. Microwell films were then placed in $70 \%$ ethanol for $15 \mathrm{~min}$ at room temperature before removing the scaffold from the mold. Before seeding the islets, the microwell scaffolds were disinfected by immersion in $70 \%$ ethanol overnight. The dimensions of individual microwells in the PEOT-PBT and poly(esterurethane) films were determined by measuring 10 random microwells of every third polymer scaffold manufactured.

\section{Immobilization of ECM molecules on culture substrates}

The thin-film PEOT-PBT and poly(ester-urethane) microwell array devices were shortly exposed to oxygen plasma at an oxygen pressure of $1.0 \mathrm{bar}$, at $40 \mathrm{~mA}$, and 200 mTorr for 10 and $20 \mathrm{~s}$, respectively. The oxygen plasma treatment was used to modify the surface chemistry of the microwell scaffold and generates, for example, aldehyde groups that can react with molecules containing free amine groups present in the ECM proteins. Subsequently, microwell scaffolds and tissue culture polystyrene plates were coated with $10 \mu \mathrm{g} / \mathrm{mL}$ of ECM proteins. The ECM proteins include FN, Col4, LN111 (Merck), LN332 (Biolamina, Sweden), and a mixture of LN111, 211, 121, 311, 411, and 511 (Merck). With a total protein concentration of $10 \mu \mathrm{g} /$ $\mathrm{mL}$, the pairwise compositions of varying ratios of $\mathrm{FN}$, Col4, and $\mathrm{LN}$ (5:5, 2:8, and 8:2) were coated at room temperature for $2 \mathrm{~h}$. After three times rinsing in phosphatebuffered saline (PBS) to remove any unbound proteins, the scaffolds were placed in cell culture inserts and transferred to ultra-low-attachment cell culture plates (Corning).

\section{Primary human islet cultures}

Human islets of Langerhans were isolated from donor pancreas at the Human Islet Isolation Laboratory, Leiden University Medical Center, Leiden, The Netherlands. Human donor islets were only used if not deemed suitable for clinical islet transplantation and if research consent was present according to national laws and regulations.

Isolated human donor islets were cultured in CMRL-1066 culture medium (Cellgro, Mediatech, VA) containing $5.5 \mathrm{mM}$ D-glucose, supplemented with 10\% FBS (GIBCO, Bleiswijk, The Netherlands), $100 \mathrm{U} / \mathrm{mL}$ streptomycin (Lonza, Verviers, Belgium), $2 \mathrm{mM}$ L-glutamine, $10 \mathrm{mM}$ HEPES (GIBCO), and $1.2 \mathrm{mg} / \mathrm{mL}$ nicotinamide (Sigma-Aldrich).

Human islets from two donors (a 49-year-old man and a 75-year-old woman) were carefully handpicked, and then, 50 islets were seeded per microwell scaffold (an islet per well), which was located in tissue culture plate $(n=3)$. Medium was refreshed every other day. Human islets were seeded on nonadherent polystyrene plates, PEOT-PBT, and poly(ester-urethane) microwell scaffolds coated with ECM proteins. Several controls were prepared by seeding islets on ultra-low adhesive plates (free-floating control), bovine serum albumin (BSA)-coated tissue culture plates, and noncoated and BSA-coated microwell scaffolds (nonrelevant protein controls) made from both individual polymers.

\section{Immunofluorescence staining}

The morphology of islets was evaluated by histological analysis and microscopy. Following fixation in $4 \%(\mathrm{w} / \mathrm{v})$ paraformaldehyde and permeabilization by $0.3 \%$ Triton for $3 \mathrm{~h}$, human islets were immunofluorescent labeled for glucagon and insulin. ${ }^{16}$ The islets were blocked with $10 \%$ normal goat serum/0.15\% Triton-X 100/10 mM PBS overnight at $4{ }^{\circ} \mathrm{C}$. The primary and secondary antibodies were diluted in $1 \%$ BSA/0.2\% Triton X-100/10 mM PBS. Staining for glucagon was performed using primary rabbit anti-glucagon (1:100; Abcam, The Netherlands), and two different secondary antibodies including biotin anti-rabbit (1:200; Abcam) and streptavidin-Alexa Fluor 488 (1:200; Abcam) to distinguish alpha from $\beta$-cell. In case of insulinpositive $\beta$-cells, guinea pig anti-insulin (1:200; Abcam) was used as the primary antibody, whereas Alexa Fluor 647 goat anti-guinea pig (1:500; Abcam) was applied as the secondary conjugated antibody. Nuclei were stained using $4^{\prime}, 6^{\prime}$ diamidino-2-phenylindole dihydrochloride (DAPI) (Abcam) for $10 \mathrm{~min}$. Each step was followed by subsequent washing in $1 \% \mathrm{BSA} / 0.2 \%$ Triton $\mathrm{X}-100$ in $10 \mathrm{mM}$ PBS. Samples were subjected to optical sectioning in axial $(z)$ dimension using a Zeiss LSM510 confocal laser scanning microscope.

\section{Glucose-stimulated insulin secretion tests}

Glucose-stimulated insulin secretion (GSIS) tests were performed using triplicate samples of 50 human islets for each condition at 3 and 7 days after seeding. Each sample was first incubated for $1 \mathrm{~h}$ in a glucose-free incubation buffer, in a modified Krebs-Ringer bicarbonate buffer with HEPES (KRBH) containing $115 \mathrm{mmol} / \mathrm{L} \mathrm{NaCl}, 5 \mathrm{mmol} / \mathrm{L}$ $\mathrm{KCL}, 24 \mathrm{mmol} / \mathrm{L} \mathrm{NaHCO}_{3}, 2.2 \mathrm{mmol} / \mathrm{L} \mathrm{CaCl} \mathrm{Cl}_{2}, 1 \mathrm{mmol} / \mathrm{L}$ $\mathrm{MgCl}_{2}, 20 \mathrm{mmol} / \mathrm{L}$ HEPES, and $2 \mathrm{~g} / \mathrm{L}$ human serum albumin (Sanquin, The Netherlands), pH 7.4. Samples were then exposed to low glucose $(1.6 \mathrm{mmol} / \mathrm{L})$, high glucose $(16.7 \mathrm{mmol} / \mathrm{L})$, and another low glucose $(1.6 \mathrm{mmol} / \mathrm{L})$ $\mathrm{KRBH}$ buffer each for $90 \mathrm{~min}$ at $37^{\circ} \mathrm{C}$. After each incubation step, samples' media were collected for insulin concentration measurements by ELISA (Mercodia, Uppsala, Sweden). Finally, the islets from each sample were collected for DNA quantification using a Quant-iT Picogreen dsDNA assay (Invitrogen). Amount of insulin release was measured after low and high glucose stimulation and normalized to the DNA of islets. Moreover, the stimulation index was calculated as a ratio of insulin value after high glucose stimulation divided by the insulin value after low glucose stimulation.

\section{Statistical analysis}

Results are presented as the mean \pm standard deviation. Statistical analysis was performed using one-way ANOVA, the least significant difference multiple comparison test, and Tukey's post hoc test by the application of SPSS statistic software (Chicago). Statistical significance was considered at a $p$-value of $\leq 0.05$. The statistical analysis was performed to compare the glucose responsiveness of human donor islets in high glucose $(16.7 \mathrm{mmol} / \mathrm{L})$, between control groups 
(noncoated and BSA coated) versus functionalized culturesubstrate, PEOT-PBT, and poly(ester-urethane) microwell scaffolds at day 3 and day 7 . In addition, the statistical difference between control groups was calculated.

\section{Results}

\section{Microwell scaffold morphology}

The poly(ester-urethane) and PEOT-PBT microwell scaffolds were fabricated using micro thermoforming, which is an adapted method ${ }^{14,15}$ (Fig. 1A). Scanning electron microscopy analysis indicated similarly shaped microwells maskaligned across the surface (Fig. 1). The process was highly accurate and reproducible, and all microwell scaffolds remained stable during handling. PEOT-PBT microwells had a circular and tapered appearance with aperture diameter of $380 \pm 5 \mu \mathrm{m}$ and bottom diameter of $300 \pm 5 \mu \mathrm{m}$, and the distance between the aperture and base was $300 \pm 10 \mu \mathrm{m}$. Poly(ester-urethane) microwells had a similar aperture diameter, but a different base diameter of $250 \pm 5 \mu \mathrm{m}$.

\section{Function of primary human islets}

The effect on glucose responsiveness of human donor islets of the culture-substrate (nontreated tissue culture plastic), PEOT-PBT, poly(ester-urethane), and flat films versus microwells islets functionality was studied at 3 and
7 days. Islets cultured on PEOT-PBT and poly(esterurethane) microwell scaffolds released significantly more insulin compared with free-floating controls (Fig. 2). Moreover, the increase in insulin secretion showed a consistent, yet discrete, tendency to be highest in islets cultured on PEOT-PBT groups. In addition, islets seeded in microwells secreted more insulin than islets seeded on flat membranes of the same materials. Furthermore, while insulin release of islets on a flat surface declined over time, insulin secretion of islets cultured in microwells increased over time.

The PEOT-PBT and poly(ester-urethane) microwell scaffolds were functionalized with FN, Col4, LN111, or LN332. Additionally, these ECM molecules with a total concentration of $10 \mu \mathrm{g} / \mathrm{mL}$ were pairwise combined at a mass ratio of 5:5, 2:8, and 8:2. After seeding the human islets into the biofunctionalized microwells, the effect of the different ECM molecules on insulin secretion at day 3 and day 7 were assessed and values were normalized to the amount of insulin secreted per DNA. The results were compared with control groups consisting of human islets cultured on nontreated and BSA-functionalized PEOT-PBT and poly(ester-urethane) microwell scaffolds. Human islets significantly increased their glucose secretion level at day 3 when cultured on biofunctionalized tissue culture polystyrene surfaces with FN, Col4, LN332, Col4:LN111 (5:5, 2:8, and 8:2), and FN: LN111 (8:2) (Fig. 3). Similar results were
FIG. 1. The structure of microwell scaffolds. (a) Schematic representation of the fabrication of microwell scaffolds using micro-back molding. (a1) Press device; (a2) backing material; (3) PEOT-PBT or poly(esterurethane) film; (a4) mold (a5) micro thermoformed microwell scaffold. Scanning electron microscope images of (b-d) mold structure for applying thermoforming on polymer films, (e, f) PEOTPBT microwell scaffold, (g) human islets in PEOT-PBT scaffold, (h, i) poly(esterurethane) microwell scaffold, (j) human islets in poly(esterurethane) microwell scaffold. Color images are available online. a
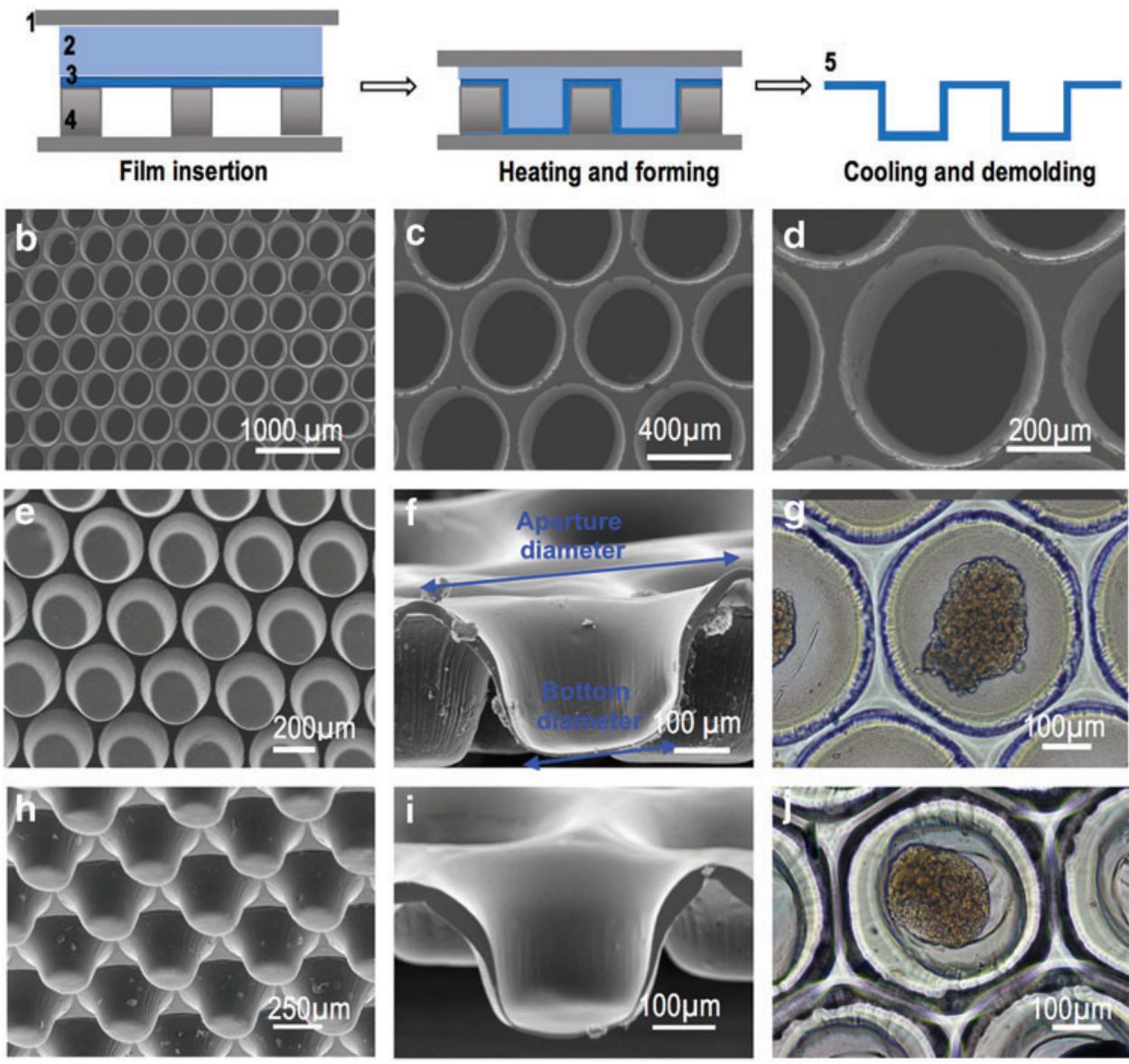


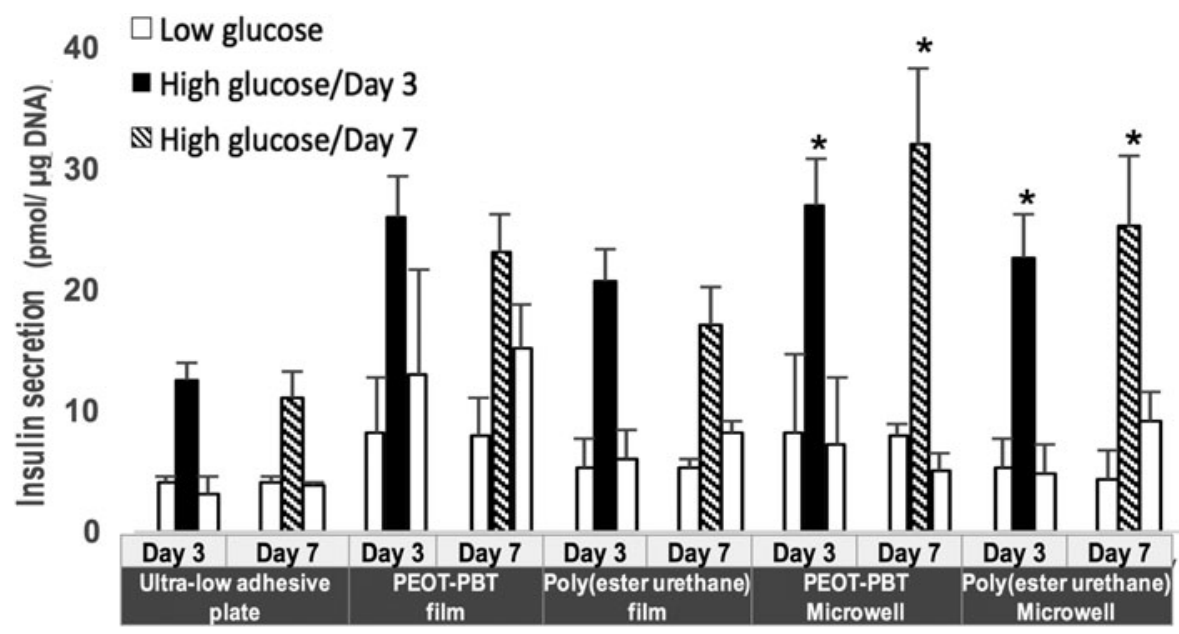

FIG. 2. Glucose-stimulated insulin secretion test of human islets on ultra-low adhesive plate (control), PEOT-PBT, and poly(esterurethane) polymer film and microwell scaffold at day 3 and day 7 . Values represent mean \pm SEM. *Indicates statistically significant differences $(p<0.05)$ for the glucose responsiveness of islets in high glucose when compared with free-floating controls at day 3 and day 7. SEM, standard error of the mean.

observed for islets from the same donors seeded into the ECM-functionalized microwell scaffolds. We observed that in general the amount of insulin secreted by islets seeded on ECM protein-functionalized PEOT-PBT scaffolds was higher than that on poly(ester-urethane) scaffolds, and significantly higher compared with islets seeded on standard tissue culture polystyrene (Fig. 4). We observed that insulin secretion in the two microwell scaffold groups (Figs. 3 and 4) in the presence of FN and Col4 shows significantly increased insulin secretion compared with their control groups (noncoated and BSA coated) on both day 3 and day 7 of culture. The insulin secretion from islets seeded on PEOT-PBT and poly(ester-urethane) microwell scaffolds, and tissue culture polystyrene coated with LN111 was lower than their control groups (noncoated and BSA coated) on day 3. However, insulin secretion increased in islets cultured in microwell scaffolds after 7 days, whereas in the tissue culture polystyrene group, no change was observed. Islets cultured on LN332coated scaffolds show an enhanced insulin secretion only after 3 days but not after 7 days. Comparison of insulin secretion of islets cultured on $\mathrm{Col} 4$ at day 7 indicates a significant better glucose response in the two microwell scaffold groups, then the polystyrene controls.

Interestingly, a significant increase in insulin secretion was observed for Col4- and LN111-coated (mass ratios used 5:5 and 8:2) scaffolds at day 3. Although at 7 days a slight decrease in insulin secretion was observed in most conditions, islets cultured on Col4:LN111-coated (8:2) microwell scaffolds showed a clear increase of insulin secretion (Figs. 3 and 4). The outcomes from islets cultured on a combination of Col4- and LN111-functionalized scaffolds show consistently that their endocrine function has significantly improved in the presence of these specific ECM proteins in comparison to all other conditions.

By comparing the islet function (see Supplementary Figures S1 and S2) in nonfunctionalized microwell scaffolds with tissue culture polystyrene, the positive influence of the 3D microwell shape on the islet's endocrine function can be analyzed. In both poly(ester-urethane) and PEOT-PBT microwell scaffolds, glucose responsiveness of islets increased between day 3 and day 7, whereas on tissue culture poly- styrene, a slight decrease of insulin release was observed. In short, islets on flat polystyrene plate as well as microwell groups functionalized with FN, Col4, LN332, and a combination of Col4 and LN111 (5:5, 2:8, and 8:2), FN and LN111 (8:2), and FN and Col4 (8:2) indicated significantly increase of glucose secretion at day 3 in comparison to their control groups (nontreated and BSA coated) at day 3 . Comparing the insulin release at day 3 and day 7 indicated the reduction in the rate of insulin release over time (from day 3 to day 7) in the presence of aforementioned ECM molecules. However, stimulation index for the flat polystyrene and PEOT-PBT and poly(ester-urethane) microwells coated with a combination of Col4:LN111 (8:2) was significantly higher than nonfunctionalized groups at both day 3 and day 7. It indicated the importance of this combination of Col4:LN111 (8:2) for the function of islets over a longer time span.

\section{Islet structure on the ECM-coated surfaces}

To assess whether the presence of ECM molecules on biomaterials can affect islet morphology, human islets were seeded on flat surface polystyrene plates functionalized with ECM molecules. The ECM proteins include FN, Col4, LN111, LN332, a mixture of LN111, 211, 121, 311, 411, and 511, as well as pairwise combinations of $\mathrm{FN}, \mathrm{Col} 4$, and LNs with a total protein concentration of $10 \mu \mathrm{g} / \mathrm{mL}$ at mass ratios of 5:5, 2:8, and 8:2. Additionally, ultra-low adhesive plates were used as free-floating controls. Islets were stained for insulin and glucagon using immunofluorescent labeling and imaged using phase-contrast transmission light and confocal fluorescent microscopy.

We observed that the islets in the free-floating control group did not adhere to the surface of nontreated plates and thus they kept their native round shape until day 7 $(99 \% \pm 0.8 \%$ of islets at day 3 and $90 \% \pm 2.1 \%$ at day 7$)$ (Fig. 5a, g). However, histological observations revealed that in these islets it seems that there are relatively less insulin-positive $\beta$-cells compared with the other conditions (Fig. 5m-r).

Human islets cultured on FN- and Col4-functionalized substrates adhered to the surface and showed cellular 


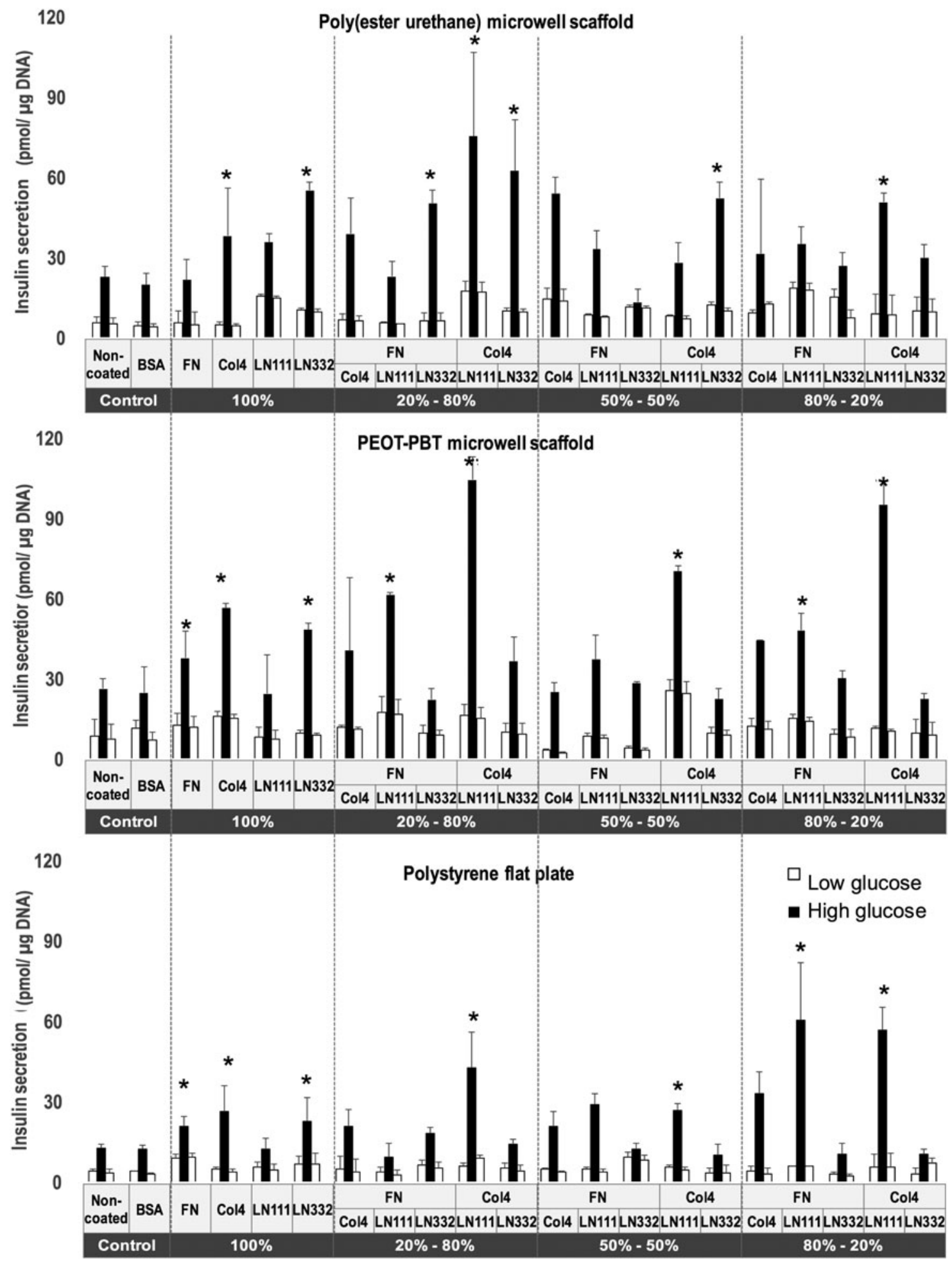

FIG. 3. Glucose-stimulated insulin secretion test of human islets on monolayer-coated ECM proteins on poly(esterurethane) microwell films (top panel), PEOT-PBT microwell films (middle panel), and polystyrene tissue culture plastic (bottom panel) with different ratios of ECM proteins at day 3. Values represent mean \pm SEM. *Indicates statistically significant differences $(p<0.05)$ for the glucose responsiveness of islets in high glucose when compared with the controls (nontreated and BSA-coated controls) at day 3. BSA, bovine serum albumin; ECM, extracellular matrix. 


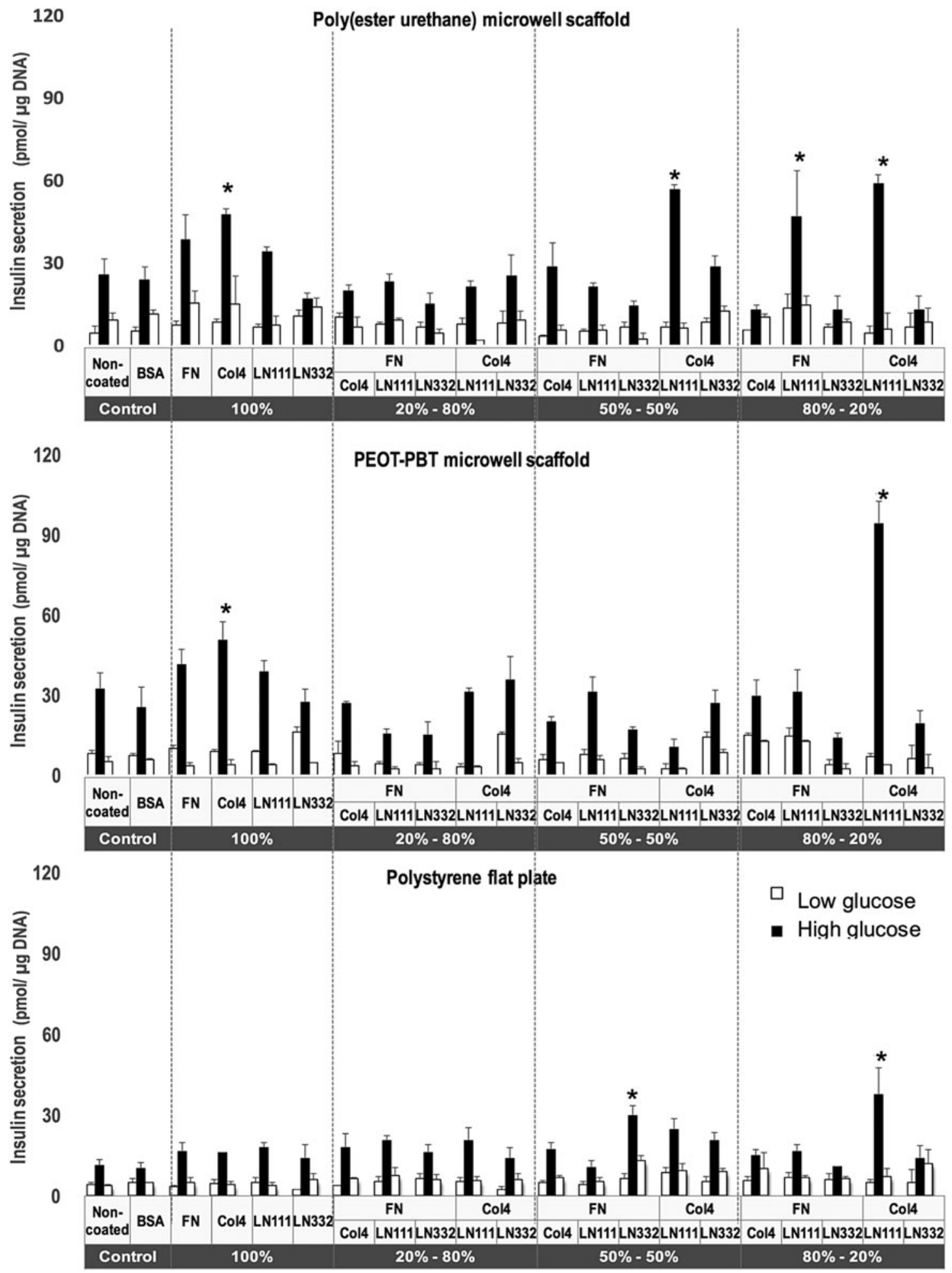

FIG. 4. Glucose-stimulated insulin secretion test of human islets on monolayer-coated ECM proteins on poly(esterurethane) microwell films (top panel), PEOT-PBT microwell films (middle panel), and polystyrene tissue culture plastic (bottom panel) with different ratios of ECM proteins at day 7. Values represent mean \pm SEM. *Indicates statistically significant differences $(p<0.05)$ for the glucose responsiveness of islets in high glucose when compared with the controls (nontreated and BSA-coated controls) at day 7. 
FIG. 5. Morphology of islets on polystyrene that was coated with FN, Col4,

LN111, LN332, and a combination of Col4 and LN111 at a ratio of 8:2 at day 3 and day 7. The islets cultured on ultra-low adhesive plates were used as a control group. (a-l) Are representative light microscopic phase contrast images at days 3 and 7, while $(\mathbf{m}-\mathbf{r})$ are representative immunofluorescent images of islets at day 7 . Color images are available online.

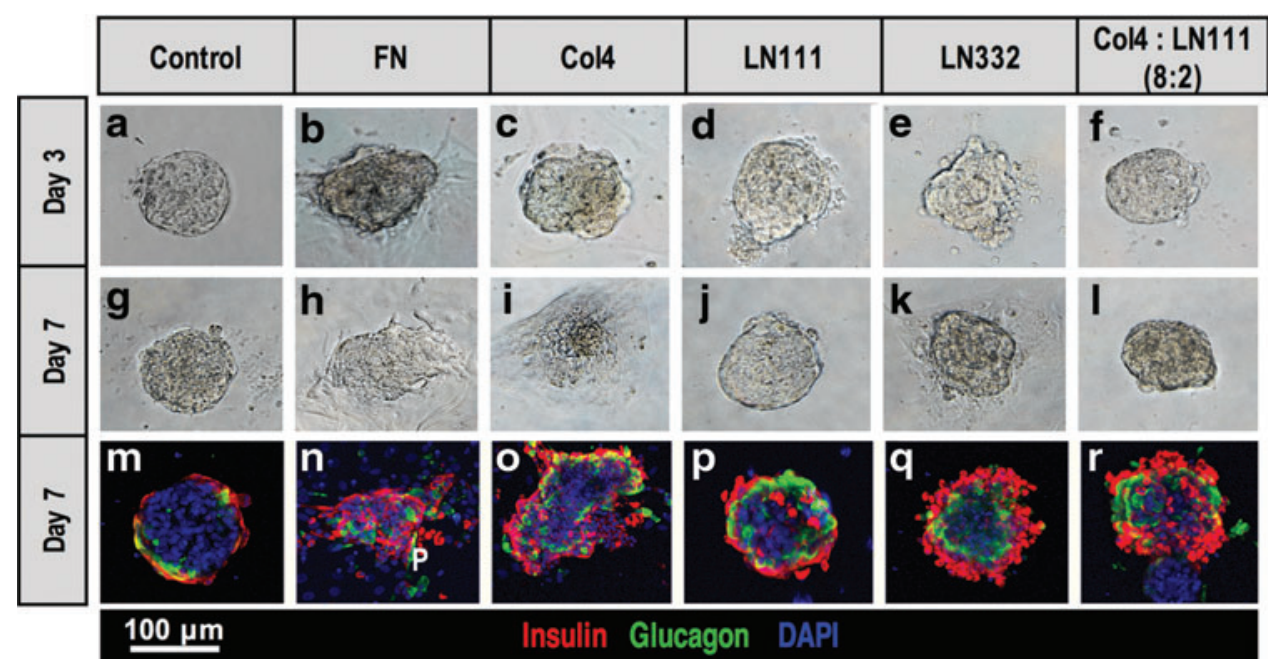

outgrowth after 7 days resulting in loss of their rounded morphology (100\% of islets) (Fig. 5h, i). In contrast, human islets cultured on LN332-functionalized substrates had only partially lost their round morphology (Fig. 5e, k). The same islets cultured on substrates with coatings of Col4 and LN111 at 5:5 and 8:2 mass ratios showed some adherence to the underlying substrate, thereby fixing the islets in place, while their original rounded morphology was preserved $(91 \% \pm 1.7 \%$ of islets) (Fig. 5f, i). Moreover, histology revealed that these islets seemed to contain a higher numbers of functional $\beta$-cells after 7 days in comparison to the other conditions (Fig. 5m-r).

\section{Discussion}

Islet transplantation is an efficient treatment for type 1 diabetes. However, it faces many obstacles such as reduced function of islets or loss of $60 \%$ of the islets in a short period of time after transplantation. ${ }^{17,18}$ In clinical islet transplantation, the islet ECM is degraded by the enzymes used during the isolation procedure. ${ }^{19}$ It was also reported that the $\beta$-cells are not the most important producers of ECM in islets, but instead capillary endothelial cells were found to be the dominant producers of basement membrane (BM), which forms a major part of the islet's ECM. ${ }^{20}$ Therefore, it is critical to support transplanted islets with external ECM molecules, particularly in the first 2 weeks, until revascularization and deposition of new ECM can take place. ${ }^{21}$ The aim of this study was to investigate the effect of specific islet ECM molecules on the endocrine function and cell behavior in human donor islets. Human islets from two different donors were used for performing the experiments because they have karyotype and function similar to in vivo situation. However, using different donors might result in donor-dependent variation in the level of insulin secretion. The selection of specific ECM molecules in this study was based on what is currently described in the literature describing their presence in the microenvironment and possible influence on the physiology of pancreatic islet cells. It is known that the signaling interaction between the ECM molecules and islet cells can regulate multiple aspects of islets physiology, such as insulin release, survival, and proliferation of $\beta$-cells. ${ }^{22}$ Naba et al. by performing quantitative proteomic profile of the ECM of normal pancreatic islets detected 120 ECM and ECM-associated proteins, which are composed of 57 ECM glycoproteins, 37 collagens, 9 proteoglycans, 23 ECM-affiliated proteins, 42 ECM regulators, and 10 secreted factors. Among these molecules, fibrillar collagens, FN, LNs, and nidogens are the most abundant molecules of the islet ECM. ${ }^{23}$ We selected FN, Col4, LN111, and LN332, which were all shown to support the function and viability of islets in previous publications. ${ }^{3,24,25}$

Not only the effect of individual proteins but also the combinatorial effect of these proteins on islets was studied. Furthermore, we compared the effect of these proteins when bound to the surface of poly(ester-urethane) or PEOT-PBT microwell scaffolds on the glucose responsiveness of human donor islets with their nonfunctionalized counterparts.

One of the drawbacks of most macroencapsulated islet delivery devices is the clustering and aggregation of islets inside these devices. Aggregation negatively affects islet morphology and function by limiting the oxygen and nutrients supply leading to necrosis in the core of islets. ${ }^{17,26,27}$ We showed that in this and previous studies that by seeding islets in individual microwells, the islet's rounded morphology can be preserved and aggregation prevented. ${ }^{14,16}$ In general, we observed in this study that islets cultured in microwell scaffolds show a higher insulin secretion in comparison to the same islets grown on flat polymer substrates. This change in islets function and morphology seems to be related to the design of the microwell scaffold's semispherical structure. In addition, each microwell acts as a physical barrier to avoid aggregation of neighboring islets. The mechanical properties of the polymer scaffolds also might have a positive influence on islets. The tissue culture polystyrene plates have a higher stiffness than both poly(ester-urethane) and PEOT-PBT, which are rather elastic polymers in part explaining the lower insulin secretion levels found in these controls. Seewaldt observed that the stiffness of ECM can induce physical changes in breast cancer cells and influence their behavior due to a phenomenon called mechanotransduction. ${ }^{28}$ To the best of our knowledge, there has not been systematic study on the 
effect of ECM stiffness and elasticity in relation to $\beta$-cell function.

Regarding the influence of ECM molecules on islets, the GSIS test indicated significant increase of insulin secretion for the islets that were seeded on substrates functionalized with either FN or Col4. The positive impact of Col4 on the function of islets in in vivo ${ }^{29}$ and in vitro ${ }^{30}$ was reported previously. Moreover, it was reported that the cultivation of islets in the presence of FN increases insulin release and preserves the viability and mass of islets after transplantation. ${ }^{24}$ Interestingly, although $\mathrm{FN}$ and Col4 molecules individually display a positive effect on islets, based on our findings the combinations of these two molecules have a negative effect on insulin secretion. In favor of this finding, Flaim et al. reported similar results regarding the function of hepatocyte cells. ${ }^{31}$ They assessed the effect of Col4 and FN on cellular differentiation of primary rat hepatocytes by immunofluorescent staining of intracellular albumin (a marker of specific liver function). Kaido et al. have described that there is a strong interaction of islets with $\mathrm{Col}$ and $\mathrm{FN}$, which can result in a transition from a rounded morphology into a monolayer-like appearance. ${ }^{29}$ It is reported that the disruption of the spheroidal architecture of the islets can possibly interfere with integrinmediated signaling and paracrine interactions between individual islet cells. ${ }^{32}$ The integrin-mediated signaling in response to the pancreatic ECM plays a crucial role in $\beta$ cell survival and insulin secretion. For instance, integrin binding to Col including $\alpha 1 \beta 1, \alpha 2 \beta 1$, and $\alpha 3 \beta 1$ integrins regulate cell adhesion, insulin gene expression, and islet survival.

Korpos et al. reported that LNs of peri-islet BM (consisting of $\mathrm{LN} \alpha 2, \alpha 4, \beta 1, \beta 2, \gamma 1, \gamma 2$, and $\gamma 3$ chains) are distinct from the LNs found in close vicinity of surrounding blood vessels (consisting $\mathrm{LN} \alpha 5, \beta 1$, and $\gamma 1$ chains). ${ }^{33}$ Since, LN $\beta 1$ and $\gamma 1$ chains are common between peri-islet ECM and the BM of surrounding blood vessels, we expected to see significant influence of LN111 on islets. Interestingly, the interaction of LN111 with islets did not positively affect insulin secretion, whereas LN111 in combination with Col4 showed a significant increase in the insulin secretion even higher than Col4 alone. It is reported that Col4 tend to bind via the intermediary glycoproteins nidogen, or entactin, or via direct interaction with heparin sulfate proteoglycans. ${ }^{34}$ Our results suggested that a combination of important ECM proteins can play a synergistic role to enhance insulin secretion of human islets. Comparing all different combinations used in this study, we found the highest level of insulin secretion in human islets cultured on a combination of Col4 and LN111 at a mass ratio of $8: 2$ with a concentration of $>5 \mu \mathrm{g} / \mathrm{cm}^{2}$ after 7 days. Histological observations revealed that islets seeded on both microwell scaffolds and flat substrates coated with Col4:LN111 (8:2) maintain their rounded shape and thus improve the function of islets even further. In addition, the semispherical structure of the microwells in the scaffold exposes the islets to an ECM-functionalized substrate almost all around their exterior, whereas in the flat substrate, the islets are only exposed to ECM at the bottom. Therefore, based on our data, we postulate that the combination of two ECM molecules (Col4 and LN111 with 8:2 mass ratio) along with specific design of microwell scaffolds could have an additional positive effect on the endocrine function possibly by a more efficient exposure to the biofunctionalized surface. But one important question still remains: Why does the insulin secretion increase so significantly if only a few cells on the exterior of islets are exposed to a biofunctionalized substrate? We think that there might be a few plausible explanations for our findings.

It is commonly accepted that insulin secretion is mediated via $\mathrm{Ca}^{2+}$; when $\beta$-cell secretes insulin, this is accompanied with a sudden raise in intracellular $\mathrm{Ca}^{2+}$ levels via an influx through specific voltage-gated channels in the cell membrane or via the release of endoplasmic reticulum-stored $\mathrm{Ca}^{2+}$ into the cytosol. Although the activation of specific signal transduction pathways triggered by integrin binding is not very well studied in $\beta$-cells, there is quite some evidence from other fields that show that integrin binding can lead to the activation of several important pathways such as MAPKs and Rho via integrin-regulated FAK/Src signaling. ${ }^{35}$ Both pathways involve an increase in cytosolic $\mathrm{Ca}^{2+}$, perhaps this increase could lead to enhanced glucose responsiveness. It is known that $\mathrm{Ca}^{2+}$ is involved in many different mechanisms in $\beta$-cells, varying from mitochondrial function to $\beta$-cell electrical activity. ${ }^{36}$ No relationship between specific integrin binding and cytosolic $\mathrm{Ca}^{2+}$ has been reported so far; therefore, we can only speculate about its role in improved insulin secretion and this only in part explains our findings. Another possible explanation could be that $\beta$-cells can act as $\beta$-cell hubs, which can drive insulin secretion in pancreatic islets. Work performed by Rutter and colleagues suggests that certain $\beta$-cells can act as pacemakers for insulin secretion in islets. They found that a small group of $\beta$-cells are leading rhythmic pulsatile insulin secretion and connect to many other $\beta$-cells in islets. ${ }^{37}$ Their finding can perhaps explain why even though only a handful of $\beta$-cells located on the outside, which are in direct contact with ECM proteins, can enhance insulin secretion so significantly in our scaffolds.

In conclusion, we indicated that islet-ECM interactions can influence the insulin secretion of human donor islets. Understanding the role of each particular ECM molecule on insulin secretion, viability and morphology of the islets are key factors to engineer biomimetic microenvironments of $\beta$ cell replacement devices to treat type 1 diabetes. We showed that exposure of islets to LN111 ( $>5 \mu \mathrm{g} / \mathrm{mL})$ in combination with other ECM proteins $(<5 \mu \mathrm{g} / \mathrm{mL})$ results in a decline in insulin secretion over time. In contrast, lower ratios of $\mathrm{LN}$ $(<5 \mu \mathrm{g} / \mathrm{mL})$ in combination with other ECM molecules led to a sustained release of insulin over a 7-day period. Both PEOT-PBT and poly(ester-urethane) microwell scaffolds functionalized with the combination of Col4 and LN111 with a mass ratio of 8:2 led to significantly enhanced insulin secretion in human donor islets.

\section{Acknowledgments}

This research was financially supported by the Diabetes Cell Therapy Initiative (DCTI) FES 2009 program LSHDCTI including the Dutch Diabetes Research Foundation (DF). Dr. J.L. acknowledges financial support from the Dutch NWO innovative research incentives scheme Veni award (\#14328) and the European Research Council (ERC, Starting Grant \#759425). 


\section{Disclosure Statement}

No competing financial interests exist.

\section{References}

1. Barton, F.B., Rickels, M.R., Alejandro, R., et al. Improvement in outcomes of clinical islet transplantation: 1999-2010. Diabetes Care 35, 1436, 2012.

2. Davis, N.E., Beenken-Rothkopf, L.N., Mirsoian, A., et al. Enhanced function of pancreatic islets co-encapsulated with ECM proteins and mesenchymal stromal cells in a silk hydrogel. Biomaterials 33, 6691, 2012.

3. Kaido, T., Yebra, M., Cirulli, V., and Montgomery, A.M. Regulation of human $\beta$-cell adhesion, motility, and insulin secretion by collagen IV and its receptor $\alpha 1 \beta 1$. J Biol Chem 279, 53762, 2004.

4. Beattie, G.M., Rubin, J.S., Mally, M.I., Otonkoski, T., and Hayek, A. Regulation of proliferation and differentiation of human fetal pancreatic islet cells by extracellular matrix, hepatocyte growth factor, and cell-cell contact. Diabetes 45, 1223, 1996.

5. Lin, H.-Y., Tsai, C.-C., Chen, L.-L., Chiou, S.-H., Wang, Y.-J., and Hung, S.-C. Fibronectin and laminin promote differentiation of human mesenchymal stem cells into insulin producing cells through activating Akt and ERK. J Biomed Sci 17, 56, 2010.

6. Yap, W.T., Salvay, D.M., Silliman, M.A., et al. Collagen IV-modified scaffolds improve islet survival and function and reduce time to euglycemia. Tissue Eng Part A 19, 2361, 2013.

7. Pinkse, G.G.M., Bouwman, W.P., Jiawan-Lalai, R., Terpstra, O.T., Bruijn, J.A., and de Heer, E. Integrin signaling via RGD peptides and anti- 1 antibodies confers resistance to apoptosis in islets of Langerhans. Diabetes 55, 312, 2006.

8. Hammar, E., Parnaud, G., Bosco, D., et al. Extracellular matrix protects pancreatic $\beta$-cells against apoptosis: role of short- and long-term signaling pathways. Diabetes 53, 2034, 2004.

9. Lucas-Clerc, C., Massart, C., Campion, J.P., Launois, B., and Nicol, M. Long-term culture of human pancreatic islets in an extracellular matrix: morphological and metabolic effects. Mol Cell Endocrinol 94, 9, 1993.

10. Nagata, N., Gu, Y., Hori, H., et al. Evaluation of insulin secretion of isolated rat islets cultured in extracellular matrix. Cell Transplant 10, 447, 2001.

11. Nagata, N., Iwanaga, A., Inoue, K., and Tabata, Y. Coculture of extracellular matrix suppresses the cell death of rat pancreatic islets. J Biomater Sci Polym Ed 13, 579, 2002.

12. Hammar, E.B., Irminger, J.-C., Rickenbach, K., et al. Activation of $\mathrm{NF}-\kappa \mathrm{B}$ by extracellular matrix is involved in spreading and glucose-stimulated insulin secretion of pancreatic beta cells. J Biol Chem 280, 30630, 2005.

13. Llacua, A., de Haan, B.J., Smink, S.A., and de Vos, P. Extracellular matrix components supporting human islet function in alginate-based immunoprotective microcapsules for treatment of diabetes. J Biomed Mater Res A 104, 2016, 1788 .

14. Buitinga, M., Truckenmüller, R., Engelse, M.A., et al. Microwell scaffolds for the extrahepatic transplantation of islets of Langerhans. PLoS One 8, e64772, 2013.
15. Truckenmüller, R., Giselbrecht, S., Rivron, N., et al. Thermoforming of film-based biomedical microdevices. Adv Mater 23, 1311, 2011.

16. Buitinga, M., Janeczek Portalska, K., Cornelissen, D.-J., et al. Coculturing human islets with proangiogenic support cells to improve islet revascularization at the subcutaneous transplantation site. Tissue Eng Part A 22, 375, 2016.

17. Lehmann, R., Zuellig, R.A., Kugelmeier, P., et al. Superiority of small islets in human islet transplantation. Diabetes 56, 594, 2007.

18. Ricordi, C., Gray, D.W.R., Hering, B.J., et al. Islet isolation assessment in man and large animals. Acta Diabet Lat 27, $185,1990$.

19. Cross, S.E., Hughes, S.J., Partridge, C.J., Clark, A., Gray, D.W.R., and Johnson, P.R.V. Collagenase penetrates human pancreatic islets following standard intraductal administration. Transplantation 86, 907, 2008.

20. Nikolova, G., Jabs, N., Konstantinova, I., et al. The vascular basement membrane: a niche for insulin gene expression and $\beta$ cell proliferation. Dev Cell 10, 397, 2006.

21. Menger, M.D., Jaeger, S., Walter, P., Feifel, G., Hammersen, F., and Messmer, K. Angiogenesis and hemodynamics of microvasculature of transplanted islets of Langerhans. Diabetes 38, 199, 1989.

22. Stendahl, J.C., Kaufman, D.B., and Stupp, S.I. Extracellular matrix in pancreatic islets: relevance to scaffold design and transplantation. Cell Transplant 18, 1, 2009.

23. Naba, A., Clauser, K.R., Mani, D.R., Carr, S.A., and Hynes, R.O. Quantitative proteomic profiling of the extracellular matrix of pancreatic islets during the angiogenic switch and insulinoma progression. Sci Rep 7, 40495, 2017.

24. Hamamoto, Y., Fujimoto, S., Inada, A., et al. Beneficial effect of pretreatment of islets with fibronectin on glucose tolerance after islet transplantation. Horm Metab Res 35, 460, 2003.

25. Jiang, F.-X., Naselli, G., and Harrison, L.C. Distinct distribution of laminin and its integrin receptors in the pancreas. J Histochem Cytochem 50, 1625, 2002.

26. Nittala, A., Ghosh, S., and Wang, X. Investigating the role of islet cytoarchitecture in its oscillation using a new $\beta$-cell cluster model. PLoS One 2, e983, 2007.

27. MacGregor, R.R., Williams, S.J., Tong, P.Y., Kover, K., Moore, W.V., and Stehno-Bittel, L. Small rat islets are superior to large islets in in vitro function and in transplantation outcomes. Am J Physiol Endocrinol Metab 290, E771, 2006.

28. Seewaldt, V. ECM stiffness paves the way for tumor cells. Nat Med 20, 332, 2014.

29. Kaido, T., Yebra, M., Cirulli, V., Rhodes, C., Diaferia, G., and Montgomery, A.M. Impact of defined matrix interactions on insulin production by cultured human $\beta$-cells. Diabetes 55, 2723, 2006.

30. Blomeier, H., Zhang, X., Rives, C., et al. Polymer scaffolds as synthetic microenvironments for extrahepatic islet transplantation. Transplantation 82, 452, 2006.

31. Flaim, C.J., Chien, S., and Bhatia, S.N. An extracellular matrix microarray for probing cellular differentiation. Nat Methods 2, 119, 2005.

32. Cabrera, O., Berman, D.M., Kenyon, N.S., Ricordi, C., Berggren, P.-O., and Caicedo, A. The unique cytoarchitecture of human pancreatic islets has implications for islet cell function. Proc Natl Acad Sci U S A 103, 2334, 2006. 
33. Korpos, É., Kadri, N., Kappelhoff, R., et al. The peri-islet basement membrane, a barrier to infiltrating leukocytes in type 1 diabetes in mouse and human. Diabetes 62, 531, 2013.

34. Olsen, B. Basement membrane collagens (type IV). In: Kreis, T. and Vale, R., eds. Guidebook to the Extracellular Matrix and Adhesion Proteins. Oxford, UK: Oxford University Press, 1993, pp. 176.

35. Mitra, S.K., and Schlaepfer, D.D. Integrin-regulated FAKSrc signaling in normal and cancer cells. Curr Opin Cell Biol 18, 516, 2006.

36. Gilon, P., Chae, H.Y., Rutter, G.A., and Ravier, M.A. Calcium signaling in pancreatic $\beta$-cells in health and in type 2 diabetes. Cell Calcium 56, 340, 2014.

37. Johnston, N.R., Mitchell, R.K., Haythorne, E., et al. Beta cell hubs dictate pancreatic islet responses to glucose. Cell Metab 24, 389, 2016.
Address correspondence to:

Elahe Hadavi, PhD

Fraunhofer Project Centre

Department of Design, Production and Management

University of Twente

Drinerlolaan 5

Hosrttower 310

7522 NB Enschede

The Netherlands

E-mail: e.hadavi@utwente.nl

Received: November 27, 2018

Accepted: January 4, 2019

Online Publication Date: February 12, 2019 